\title{
MicroCT Analisys of Dental Adhesives Loaded with Nanoparticles
}

\begin{abstract}
CRISTIAN ZAHARIA ${ }^{1}$, COSMIN SINESCUㄴ, ALIN-GABRIEL GABOR ${ }^{1}$, ANDREEA CODRUTA COJ OCARIU', VLAD SOCOLIUC², CAMELIA SZUHANEK'*, MEDA-LAVINIA NEGRUTIU ${ }^{1}$

${ }^{1}$ Victor Babes University of Medicine and Pharmacy, Faculty of Dental Medicine, 9 Revolutiei 1989 Blv., 300070, Timisoara, Romania

${ }^{2}$ Romanian Academy - Timisoara Branch, Center for Fundamental and Advanced Technical Research, Laboratory of Magnetic Fluids, Mihai Viteazu Ave. 24, 300223 Timisoara, Romania

Dental decay is an infectious disease that affects more and more people. Dental Restoration Materials are not infallible, after filling a tooth with composite materials, and secondary caries may appear. One of the possible causes involved in the appearance of secondary caries is generated by the uneven thickness of the layer of adhesive that can be fractured by microinfiltration areas. The purpose of this study is to evaluate a new type of dental adhesive that has been loaded with ferric nanoparticles. The thickness of the adhesive layer used in the restoration of the various types of cavities on the surface of the teeth, which were coated with copolymerizable composite materials, was evaluated, making a comparison between the thickness of the uncoated adhesive layer and the thickness of the adhesive loaded with ferric nanoparticles.In this study, 20 extracted teeth were used which presented various carious lesions. The dental caries were removed resulting class I and II Black cavities. The restoration of the cavities was made using adhesive techniques and photopolymerizable fluid-type composites, the adhesive layer being analyzed by the microCT.
\end{abstract}

Keywords: dental adhesive, nanoparticles, microCT, adhesive thickness

Dental caries are a common affection on a large scale. The most popular dental restorative materials are composite resins, adhering to the surface of the teeth using adhesive systems [1].

Today dental adhesives have a wide range of uses. Direct composite restorations in the frontal or lateral areas of the arch require the use of dental adhesives. These adhesives are also required during cementing of composite prosthetic restorations made in the dental laboratory such as inlays, onlays, crowns or veneers [2].

Despite improvements in the properties of composite materials, phenomena such as fracture of the restoration, chipping and discoloration may occur, the dentistneeding to repair or replace that obturation [3].

The main reason for the replacement of dental fillings made of composite is the appearance of secondary caries. The treatment of secondary caries consists of replacing old dental fillings to avoid advancing caries to the pulp chamber or root canals, which can lead to endodontic treatment or even to the loss of the tooth. Degradation of the adhesive from the tooth interface results in marginal infiltrations colonized by bacteria that will produce enzymes and acids that facilitate the onset of secondary caries [4].

The concept of the generation of adhesives introduced in the early 1990s is to demineralize enamel and dentine at the same time with phosphoric acid. To avoid collapsing collagen, the dentin surfaces have to remain moist, applying the primer to infiltrate the exposed collagen network. The primary purpose of the hybridization is to allow increased bond strength and dentinal sealing. At the end of the 90's, two-steps total etch adhesive systems and two-steps self-etch adhesives were introduced, with recent developments in adhesive technologies significantly reducing handling times[5].
Matsui, Gwinnett, and Buonocore showed the effect of conditioning the enamel with phosphoric acid. The treated surfaces showed after demineralization resin-tags, the applied resins penetrating into these polygons and increasing adhesion. The principle in which phosphoric acid applied to the surface of enamel to increase adhesion will be embraced by clinicians much later [6].

Dental adhesives have evolved over recent years from the no-etch system to total etch systems and self-etch systems [7].

The need for simplified clinical procedures has led to the evolution of adhesive dental technology. Evolution of dentinal adhesives generated decreased postoperative dental sensitivity as well as shortening work steps for composite restorations, compared to systems used to deminerate and wash the acid used before applying the adhesive [8].

Starting with 2011, universal adhesives have been introduced into the current practice. The appearance of universal adhesives leads to the use of simpler protocols, namely one-step self-etch (SE) or two-step etch-and-rinse (ER) $[9,10]$.

Generations of single-step self-etch adhesives have shown some weaknesses. In order to obtain a durable bond over time, universal adhesives developed later, allow their application after the surface has been pre-demineralized with phosphoric acid, the tests performed showing good in vitro results [11].

The coefficient of thermal expansion of the restoration materials is different compared with the dental tissues, which is why at level of interface between the tooth and the restoration material there may be tensions that will lead to microinfiltration. Due to thermal fatigue, the reduction in adhesion strength may indicate the potential

* email :cameliaszuhanek@umft.ro.Phone: +40724251240 
for incidence of microinfiltration when using auto-etch adhesive systems [12].

The most affected property when using adhesive systems is tightness, adhesion being proportional to microinfiltrations [13].

Within the self-etch monocomponent adhesive systems, the acidic characteristics of the active monomers make removal of the smear layer and dissolution of the dentin beneath it. The mineral content of the dentin buffers the acidity of the continuous glue monomers, the demineralization being limited. The morphological appearance of the surface where the adhesive will be applied depends on the aggressiveness of the acid monomers in the composition, as well as on the morphology of the dentin surface [14].

Self-etch adhesive systems may present different microinfiltration areas, even if the protocol of use it's the same [15-17].

Bonding agents are subjected to a variety of chemical and physical attacks in the mouth. Dissolution, biological forces and diffusion caused by marginal microinfiltrations can attack the dental adhesive layer. A consequence of this may be the degradation of the hydrolytic bond in the dentin-resin interface area. The polymerization contraction can generate physical and mechanical forces which, together with temperature variations and masticatory forces, can be absorbed by the surface of the adhesive, which functions as an elastic buffer. All of these will have an equal distribution if the adhesive layer has an uniform thickness [18].

The technique of applying adhesive materials, as well as the differences in materials, can influence the strength of adhesion, marginal adaptation, radiopacity, marginal sealing, and the thickness of the adhesive film. Adhesives found in a single bottle may have a higher resistance than those present in different primer / adhesive components [19].

Dental adhesion studies are of interest, being evaluated from a variety of perspectives: direct composite restorations evaluated with Time Domain Optical Coherence Tomography, dental adhesives used in orthodontic treatments and microleackage analisys in class $\mathrm{V}$ compomer-filled cavities [20-22].

\section{Experimental part}

The restoration techniques used in this study were adhesive type, using the Evetric Bond (Ivoclar) dental adhesive and the Brilliant Flow (Coltene) fluid composite.
For 10 samples the unmodified adhesive was used and for the other 10 samples the adhesive was loaded with magnetic nanoparticles: Fe304-SiO2 multicore-shell (MCSMP) and singlecore $\mathrm{Fe}_{3} \mathrm{O}_{4}$ particles (SCMP).

After the cavities were prepared, the teeth were demineralized with phosphoric acid for 15 s on the surface of the dentin and $30 \mathrm{~s}$ on the enamel surface. After demineralisation, the teeth were washed with water for $20 \mathrm{~s}$ and air-dried. The non-loaded magnetic nanoparticle adhesive was applied to the prepared 10-teeth surface and brushed for 20 sfollowing polymerization with a light-curing light with blue light for $20 \mathrm{~s}$.

For the other samples, the adhesive was charged with magnetic nanoparticles and mixed for $5 \mathrm{~s}$, then applied in the prepared surface of the teeth and brushed for 20 seconds. After application, it was polymerized with the light-blue light-curing lamp. Both layers of adhesive were pre-blown with airjetfor $5 \mathrm{~s}$. After the photo-polymerization of the adhesive layer, the filling of the fluid composite was completed and its photopolymerization was completed for $40 \mathrm{~s}$.

The 20 samples were analyzed using the microCT. The teeth used in the study were positioned in supports specially designed for easier handling during scanning. Scanning was made using the Nikon XTH-450 microCT (fig.1). Scanning was performed by rotating the 360 degree probe and capturing 1000 projections using a 90 microA tube tension.

The scanning images were imported into Vg Studio Max and the three-dimensional samples reconstruction was carried out. During the analysis, was observed the thickness of the adhesive layer not containing the magnetic nanoparticles applied on the prepared surface of the control samples (fig.2).

Following the microCT analysis, the samples probes showed adhesive layer thicknesses ranging from $0.02 \mathrm{~mm}$ to $0.34 \mathrm{~mm}$. It is possible to observe the surfaces of the adhesive layer uncoated with magnetic particles, the layer exhibiting uneven thicknesses, where the green color represents $0.2 \mathrm{~mm}$ thick and the blue represents thicknesses of about $0.34 \mathrm{~mm}$ (figs. 3-5).

The three-dimensional reconstruction of the samples to which the dental adhesive was loaded with magnetic nanoparticles was also generated using Vg Studio Max. Their generation used the same protocol utilized for the sample probes and in rendering samples to which the dental adhesive was not loaded with magnetic nanoparticles (fig.6).

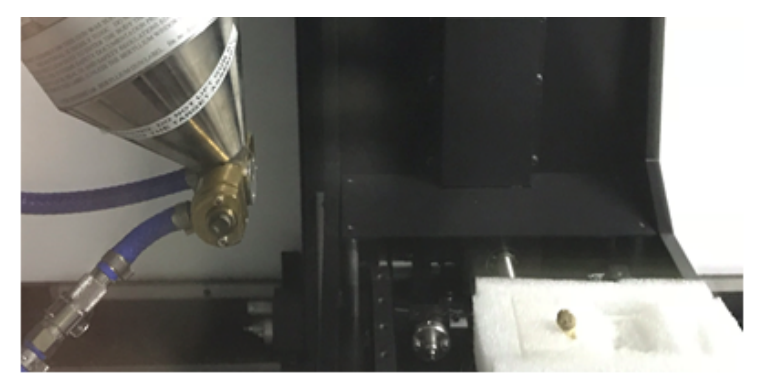

Fig.1. MicroCT analisys with Nikon XTH-450

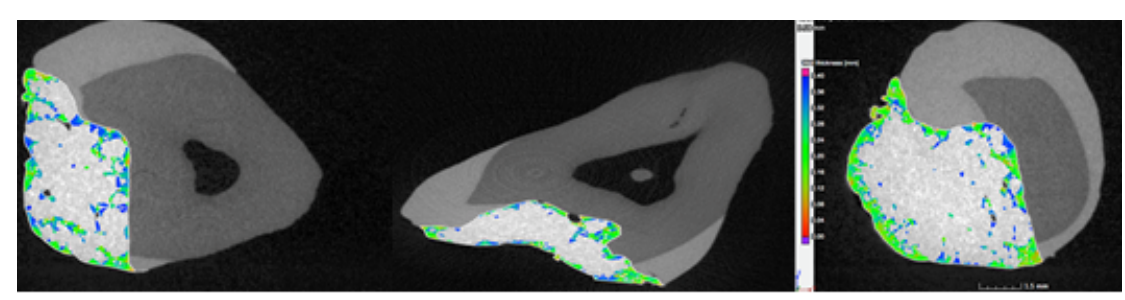

Fig.2. Top, mesial and frontal view of a tooth with adhesive without magnetic nanoparticles 


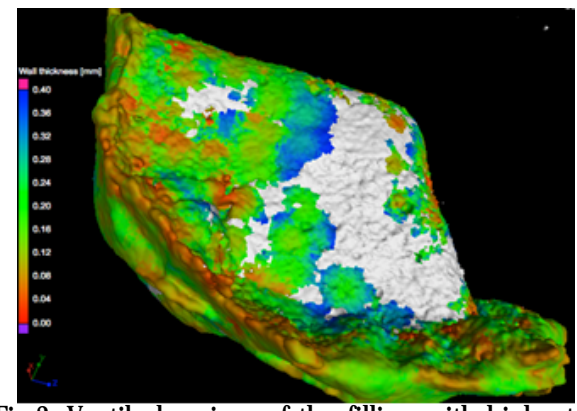

Fig.3. Vestibular view of the filling with highest layer thickness of the sample probe

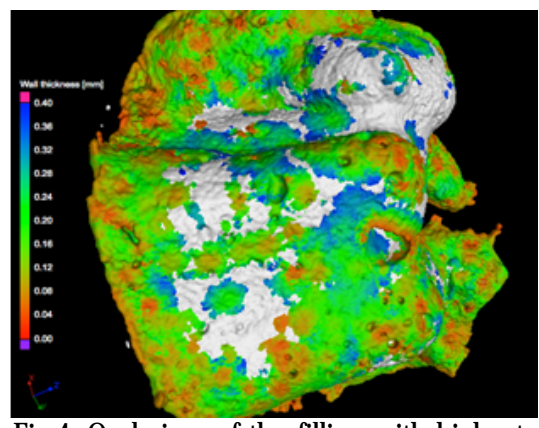

Fig.4. Oral view of the filling with highest layer thickness of the sample probe

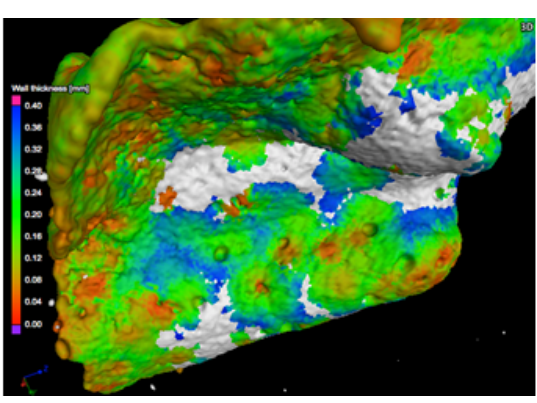

Fig.5. Pulpal view of the filling with highest layer thickness of the sample probe
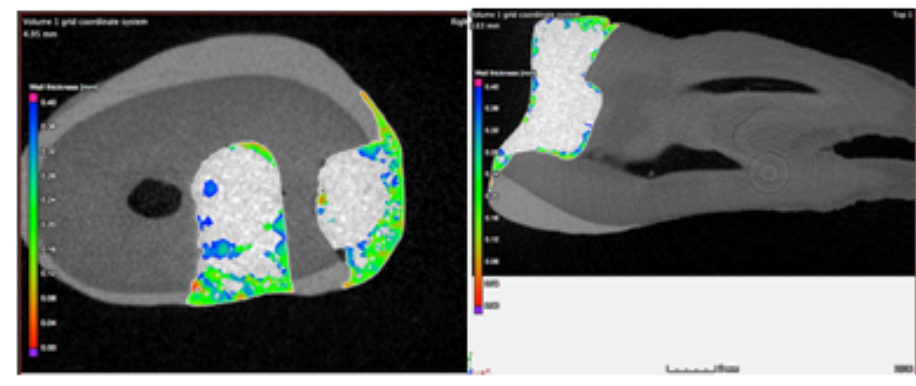

The analysis of the adhesive surfaces loaded with metallic nanoparticles generated thicknesses of the adhesive layer ranging from $0.02 \mathrm{~mm}$ to $0.38 \mathrm{~mm}$ (figs.79).

The minimum thickness of the film loaded with magnetic nanoparticles was evenly distributed, this dropping below the maximum values in many of the analyzed areas, where the deviation in $\mathrm{mm}$ of the thickness of the adhesive layer was $0.08 \mathrm{~mm}$.

The three-dimensional reconstructions show elevated surfaces of the adhesive film where the thickness is between $0.02 \mathrm{~mm}$ and $0.16 \mathrm{~mm}$.

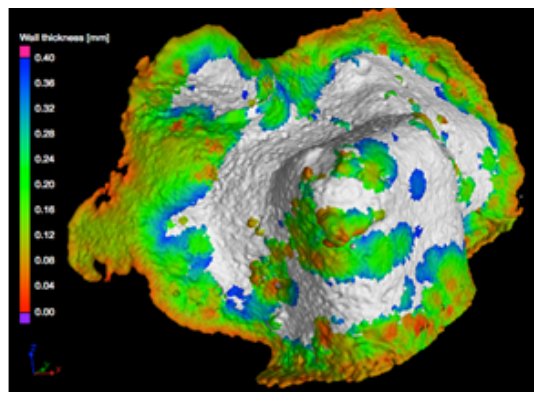

Fig.7. Vestibular view of the filling with highest layer thickness of the probes with adhesive reinforced with magnetic nanoparticles

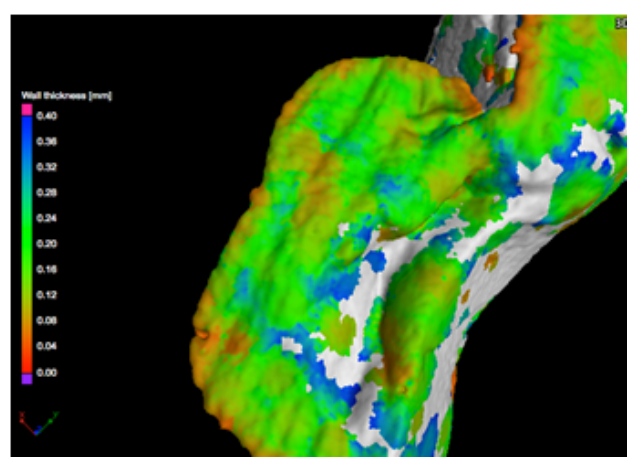

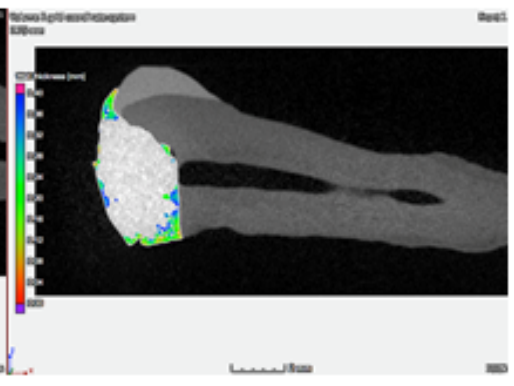

Fig.6. Top, mesial and frontal view of a tooth with adhesive without magnetic nanoparticles

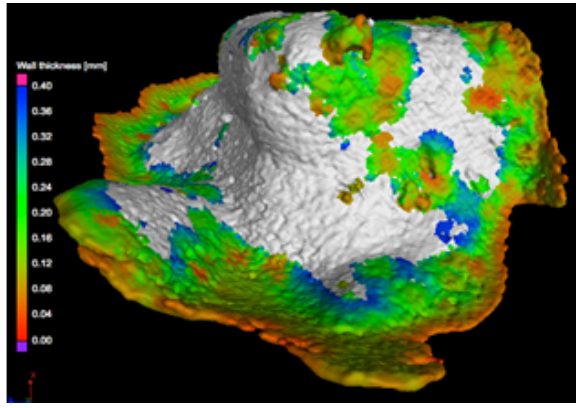

Fig.9. Pulpal view of the filling with highest layer thickness of the probes with adhesive reinforced with magnetic nanoparticles

\section{Results and discussions}

The performed microCT analyzes involved the vestibular, oral and pulp areas of the teeth.

Samples in which the adhesive was not loaded with magnetic nanoparticles showed a thickness of the adhesive layer varying between $0.02 \mathrm{~mm}$ and $0.34 \mathrm{~mm}$, the adhesive layer surfaces where the thickness is minimal being on average for a volume of $10.9 \mathrm{~mm}^{3}$ (table 1 ).

In the nexttable are presented variations in the thickness of the adhesive layer loaded with magnetic nanoparticles on all the surfaces concerned. The thickness of the layer loaded with metallic nanoparticles varies between 0.02 $\mathrm{mm}$ and $0.38 \mathrm{~mm}$, the dental surfaces containing 0.02 $\mathrm{mm}$ thickness of the adhesive layer being distributed in a much larger number (table.2).

The thickness of the adhesive layer varies according to the areas where it was analyzed, being generally close to $0.02 \mathrm{~mm}$, being close to the value generated in previous studies [19, 23].

Fig.8. Oral view of the filling with highest layer thickness of the probes with adhesive reinforced with magnetic nanoparticles 


\begin{tabular}{|c|c|c|c|c|c|}
\hline $\begin{array}{l}\text { Min. thickness } \\
\text { [mm] }\end{array}$ & $\begin{array}{l}\text { Max. thickness } \\
{[\mathrm{mm}]}\end{array}$ & Pos. $x$ [vox] & Pos. y [vox] & Pos. $z$ [vox] & Volume [mm] \\
\hline 0.34 & 0.4 & 163 & 221 & 149 & 0.03 \\
\hline 0.28 & $0, .36$ & 135 & 249 & 110 & 0.02 \\
\hline 0.25 & 0.4 & 162 & 300 & 155 & 0.01 \\
\hline 0.15 & 0.35 & 171 & 318 & 122 & 0.03 \\
\hline 0.13 & 0.39 & 150 & 291 & 116 & 0.01 \\
\hline 0.11 & 0.33 & 84 & 303 & 200 & 0.02 \\
\hline 0.1 & 0.4 & 100 & 317 & 212 & 0.02 \\
\hline 0.1 & 0.36 & 100 & 341 & 198 & 0.02 \\
\hline 0.1 & 0.22 & 108 & 354 & 101 & 0.01 \\
\hline 0.09 & 0.16 & 90 & 299 & 110 & 0.01 \\
\hline 0.08 & 0.32 & 110 & 246 & 66 & 0.01 \\
\hline 0.07 & 0.39 & 168 & 251 & 184 & 0.03 \\
\hline 0.07 & 0.35 & 168 & 308 & 138 & 0.01 \\
\hline 0.06 & 0.38 & 74 & 263 & 158 & 0.07 \\
\hline 0.06 & 0.4 & 82 & 304 & 176 & 0.05 \\
\hline 0.06 & 0.4 & 147 & 180 & 173 & 0.1 \\
\hline 0.02 & 0.4 & 24 & 122 & 123 & 10.9 \\
\hline
\end{tabular}

Table 1

ADHESIVE LAYER DISTRIBUTION IN SAMPLE PROBES

\begin{tabular}{|c|c|c|c|c|c|}
\hline $\begin{array}{c}\text { Min. thickness } \\
\text { [mm] }\end{array}$ & $\begin{array}{c}\text { Max. } \\
\text { thickness } \\
{[\mathrm{mm}]}\end{array}$ & $\begin{array}{c}\text { Pos. } x \\
\text { [vox] }\end{array}$ & $\begin{array}{c}\text { Pos. y } \\
\text { [vox] }\end{array}$ & $\begin{array}{c}\text { Pos. } z \\
{[\text { vox] }}\end{array}$ & $\begin{array}{c}\text { Volume } \\
{\left[\mathrm{mm}^{2}\right]}\end{array}$ \\
\hline 0.38 & 0.4 & 187 & 84 & 113 & 0.01 \\
\hline 0.29 & 0.36 & 150 & 168 & 88 & 0.01 \\
\hline 0.16 & 0.4 & 157 & 119 & 69 & 0.01 \\
\hline 0.16 & 0.4 & 156 & 88 & 119 & 0.03 \\
\hline 0.1 & 0.33 & 144 & 88 & 132 & 0.02 \\
\hline 0.1 & 0.4 & 164 & 138 & 151 & 0.04 \\
\hline 0.1 & 0.33 & 123 & 183 & 156 & 0.01 \\
\hline 0.09 & 0.4 & 164 & 164 & 118 & 0.02 \\
\hline 0.04 & 0.13 & 307 & 29 & 191 & 0.01 \\
\hline 0.02 & 0.4 & 269 & 109 & 51 & 25.12 \\
\hline
\end{tabular}

Table 2

ADHESIVE LAYER DISTRIBUTION IN PROBES WITH ADHESIVE REINFORCED WITH MAGNETIC NANOPARTICLES

\section{Conclusions}

Reducing the adhesive layer can reduce microinfiltration. The thickness of the adhesive layer for samples where the adhesive was loaded with metallic nanoparticles showed an increased volume of areas where its thickness was $0.02 \mathrm{~mm}$, the adhesive layer being punctiformally analyzed for the teeth in which the adhesive was loaded with nanoparticles magnetic properties being slightly diminished.

Acknowledgement: This research was partially supported by the PhD grant of the Victor Babes University of Medicine and Pharmacy of Timisoara -3712/01.10.2015 (contractno.11521/01.10.2015).
References

1. WEN ZHOU, SHIYU LIU, XUEDONG ZHOU, MATTHIAS HANNIG, STEFAN RUPF, I IN FENG, XIAN PENG, LEI CHENG, Modifying Adhesive Materials to Improve the Longevity of Resinous Restorations, Int. J. Mol. Sci. 2019, 20(3), 723; https://doi.org/10.3390/ijms20030723 2. CAMILLO D'ARCANGELO, LORENZO VANINI, MATTEO CASINELLI, MASSIMO FRASCARIA, FRANCESCO DE ANGELIS, MIRCO VADINI, MAURIZIO D'AMARIO, Adhesive Cementation of Indirect Composite Inlays and Onlays: A Literature Review, Compendium 2015, vol. 36-8 3. HAMANO N, INO S, FUKUYAMA T, HICKEL R, KUNZELMANN KH., Repair of silorane-based composites: microtensile bond strength of siloranebased composites repaired with methacrylate-based composites. Dent Mater J . 2013;32(5):695-701 
4. SPENCER P, YE Q, SONG L, PARTHASARATHY R, BOONE K, MISRA A, TAMERLER $C$, Threats to adhesive/dentin interfacial integrity and next generation bio-enabled multifunctional adhesives., J Biomed Mater Res B Appl Biomater. 2019 Mar 20. doi: 10.1002/jbm.b.34358.

5. ESHRAK SOFAN, AFRAH SOFAN, GASPARE PALAIA, GIANLUCA TENORE, UMBERTO ROMEO, GUIDO MIGLIAU, Classification review of dental adhesive systems: from the IV generation to the universal type, Annali di Stomatologia 2017, VIII (1):1-17

6. SEZINANDO A., Looking for the ideal adhesive-A review. Rev port Estomatol Med Dent Cir Maxilofac. 2014;(4):194-206.

7. J OSEPH P, YADAV C, SATHEESH K, RAHNA R., COMPARATIVE EVALUATION OF THE BONDING EFFICACY OF SIXTH, seventh and eight generation bonding agents: An in vitro study. Int Res J Pharm. 2013;4(9):143-147.

8. MARCELO GIANNINI, PATRÍCIA MAKISHI, ANA PAULA ALMEIDA AYRES, PAULO MOREIRA VERMELHO, BRUNA MARIN FRONZA, TORU NIKAIDO, JUNJI TAGAMI, Self-Etch Adhesive Systems: A literature Review, Brazilian Dental J ournal (2015) 26(1): 3-10

9. HANABUSA M, MINE A, KUBOKI T, MOMOI Y, VAN ENDE A, VAN MEERBEEK B, DE MUNCK J, Bonding effectiveness of a new multimode adhesive to enamel and dentine. J Dent. 2012;40(6):475-484.

10. MUNOZMA, LUQUEI, HASS V, REISA, LOGUERCIO AD, BOMBARDA $\mathrm{NH}$, Immediate bonding properties of universal adhesives to dentine. J Dent. 2013;41(5):404-411

11. MUNOZ MA, LUQUE-MARTINEZ I, MALAQUIAS P, HASS V, In vitro longevity of bonding properties of Universal Adhesives to dentin. Operative Dentistry. 2015:40-41

12. SAYED MOSTAFA MOUSAVINASAB, MAEDE GHASEMI, MITRA YADOLLAHI, Evaluation of Enamel and Dentinal Microleakage in Class II SiloraneBased and Methacrylate-Based Resin Composite Restorations Using Specific and Nonspecific Adhesives, J Dent (Tehran). 2018 Jul;15(4):240-249.

13. ANJ ALI GUPTA, PRADEEP TAVANE, PANKAJ KUMAR GUPTA, BELLAM TEJOLATHA, ASHIK ALI LAKHANI, RAM TIWARI, SHRUTI KASHYAP, GAURAV GARG, Evaluation of Microleakage with Total Etch, Self Etch and Universal Adhesive Systems in Class V Restorations: An In vitro Study, J Clin Diagn Res. 2017 Apr; 11(4): ZC53-ZC56

14. ANJ ALI GUPTA, PRADEEP TAVANE, PANKAJ KUMAR GUPTA, BELLAM TEJOLATHA, ASHIK ALI LAKHANI, RAM TIWARI, SHRUTI KASHYAP, GAURAV GARG, Evaluation of Microleakage with Total Etch, Self Etch and Universal Adhesive Systems in Class V Restorations: An In vitro Study, DOI: 10.7860/J CDR/2017/24907.9680

15. NAIR M, PAUL J, KUMAR S, CHAKRAVARTHY Y, KRISHNA V, SHIVAPRASAD, Comparative evaluation of the bonding efficacy of sixth and seventh generation bonding agents: An In-Vitro study. J Conserv Dent. 2014;17:27-30

16. TABARI M, ESMAEILI B, ALIMOHAMMADI M, BEJEH MIR AP, GHAREKHANI S, HAJIAHMADI M, ET AL, Comparative evaluation of microleakage of composite restorations using fifth and seventh generations of adhesive systems. Caspian J Dent Res. 2014; 3:14-19 17. KAMBALE S, HEDGE V, MUNAVALLI A, RAMESH S, BANDEKAR DS, Effect of single step adhesives on the marginal permeability of class v resin composites - an in vitro Study. IOSR JDMS. 2014;13:44-49 18. ESGROSSMAN, SSETZER, Bonding agents: adhesive layer thickness and retention to cavity surfaces with time, S Afr Dent J 2001; 56: 266272

19. MARIA JACINTA SANTOS, MARIA FIDELA LIMA NAVARRO, LAURA TAM, DOROTHY MCCOMB, The effect of dentin adhesive and cure mode on film thickness and microtensile bond strength to dentin in indirect restorations, Operative Dentistry, 2005, 30-1, 50-57,

20.SINESCU, C., MARSAVINA, L., NEGRUTIU, M.L., RUSU,L.C., ARDELEAN, L., ROMINU, M., ANTONIAC,I., TOPALA, F.I., PODOLEANU, A., New metallic nanoparticles modified adhesive used for time domain optical coherence tomography evaluation of class II direct composite restoration, Rev. Chim.(Bucharest), 63, no.4, 2012, p.380383

21.SZUHANEK, C., GOLBAN, D.M., NEGRU, R., NEGRUTIU,M.L., MARSAVINA, L., DUMA, V.F., SINESCU,C., POROJAN, L., Flash-Free Orthodontic Adhesive System Compared with the Conventional Direct Bonding Method, Rev. Chim.(Bucharest), 69 , no.11, 2018, p.40934095

22. ROMINU, M., FLORITA, Z., ROMINU, R.O., SINESCU,C., NEGRUTIU, M.L., PETRESCU, E.L., POP, D.M., ENESCU,M., TUDOR, A., The Influence of Silanes on Microleakage in Class $V$ Compomerfilled Cavities, Rev. Chim.(Bucharest), 62, no. 8, 2011.

23. K.K. CHOI, J.R. CONDON, J .L. FERRACANE, The Effects of Adhesive Thickness on Polymerization Contraction Stress of Composite, J ournal of Dental Research, March 2000, Volume 79 Issue 3

Manuscript received: 15.09 .2018 